\title{
A GPS-Based Pitot-Static Calibration Method Using Global Output-Error Optimization
}

\author{
John V. Foster* and Kevin Cunningham ${ }^{\dagger}$ \\ NASA Langley Research Center, Hampton, VA, 23681-2199
}

\begin{abstract}
Pressure-based airspeed and altitude measurements for aircraft typically require calibration of the installed system to account for pressure sensing errors such as those due to local flow field effects. In some cases, calibration is used to meet requirements such as those specified in Federal Aviation Regulation Part 25. Several methods are used for in-flight pitot-static calibration including tower fly-by, pacer aircraft, and trailing cone methods. In the 1990's, the introduction of satellite-based positioning systems to the civilian market enabled new inflight calibration methods based on accurate ground speed measurements provided by Global Positioning Systems (GPS). Use of GPS for airspeed calibration has many advantages such as accuracy, ease of portability (e.g. hand-held) and the flexibility of operating in airspace without the limitations of test range boundaries or ground telemetry support. The current research was motivated by the need for a rapid and statistically accurate method for in-flight calibration of pitot-static systems for remotely piloted, dynamically-scaled research aircraft. Current calibration methods were deemed not practical for this application because of confined test range size and limited flight time available for each sortie. A method was developed that uses high data rate measurements of static and total pressure, and GPSbased ground speed measurements to compute the pressure errors over a range of airspeed. The novel application of this approach is the use of system identification methods that rapidly compute optimal pressure error models with defined confidence intervals in nearreal time. This method has been demonstrated in flight tests and has shown 2- $\sigma$ bounds of approximately $0.2 \mathrm{kts}$ with an order of magnitude reduction in test time over other methods. As part of this experiment, a unique database of wind measurements was acquired concurrently with the flight experiments, for the purpose of experimental validation of the optimization method. This paper describes the GPS-based pitot-static calibration method developed for the AirSTAR research test-bed operated as part of the Integrated Resilient Aircraft Controls (IRAC) project in the NASA Aviation Safety Program (AvSP). A description of the method will be provided and results from recent flight tests will be shown to illustrate the performance and advantages of this approach. Discussion of maneuver requirements and data reduction will be included as well as potential applications.
\end{abstract}

\section{Nomenclature}

Symbols

$\mathrm{crb}$

$\mathrm{k}_{1}, \mathrm{k}_{2}$

$\mathrm{N}_{\mathrm{z}}$

$\mathrm{p}$

$\mathrm{q}_{\mathrm{ci}}$

$\mathrm{q}_{\mathrm{c}}$

$\mathrm{V}_{\mathrm{c}}$

$\mathrm{V}_{\mathrm{g}}$

$\mathrm{V}_{\mathrm{ge}}$

$\mathrm{V}_{\mathrm{gn}}$

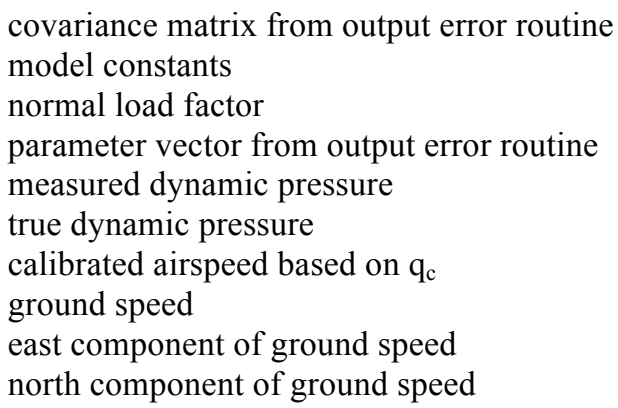

\footnotetext{
* Senior Research Engineer, Flight Dynamics Branch, MS 308, AIAA Associate Fellow.

${ }^{\dagger}$ Senior Research Engineer, Flight Dynamics Branch, MS 308, AIAA Senior Member.
} 


$\begin{array}{ll}\mathrm{V}_{\mathrm{i}} & \text { indicated airspeed based on } \mathrm{q}_{\mathrm{ci}} \\ \mathrm{V}_{\mathrm{pos}} & \text { airspeed correction due to static source position error } \\ \mathrm{V}_{\mathrm{t}} & \text { true airspeed } \\ \mathrm{V}_{\mathrm{te}} & \text { east component of true airspeed } \\ \mathrm{V}_{\mathrm{tn}} & \text { north component of true airspeed } \\ \mathrm{V}_{\mathrm{w}} & \text { wind speed } \\ \Delta \mathrm{p} & \text { pressure error, } \mathrm{q}_{\mathrm{c}}-\mathrm{q}_{\mathrm{ci}} \\ \Delta \mathrm{V} & \text { airspeed error, } \mathrm{V}_{\mathrm{c}}-\mathrm{V}_{\mathrm{i}} \\ \rho & \text { air density } \\ \sigma & \text { standard deviation } \\ \Psi_{\mathrm{w}} & \text { wind direction } \\ \text { Acronyms } & \\ \text { AvSP } & \text { Aviation Safety Program } \\ \text { AirSTAR } & \text { Airborne Subscale Transport Aircraft Research } \\ \text { GPS } & \text { Global Positioning System } \\ \text { IRAC } & \text { Integrated Resilient Aircraft Controls } \\ \text { KCAS } & \text { Calibrated airspeed, knots } \\ \text { NASA } & \text { National Aeronautics and Space Administration } \\ \text { OE } & \text { Output Error routine } \\ \text { RF } & \text { Radio Frequency } \\ \text { SIDPAC } & \text { System Identification Programs for AirCraft } \\ \text { WVR } & \text { Within Visual Range } \\ & \end{array}$

\section{Introduction}

The Airborne Subscale Transport Aircraft Research (AirSTAR) project has been developed as part of NASA's Aviation Safety Program (AvSP) and it involves a variety of unmanned flight vehicles ranging from small propeller powered aircraft to complex dynamically-scaled turbine powered aircraft. The purpose of these vehicles is to conduct flight research in regions of the flight envelope that are considered unsafe or too costly for full-scale manned vehicles. The ultimate goal of this research capability is to contribute to improvements in commercial aviation safety. A description of the AirSTAR project is provided in references 1 and 2.

A requirement of the AirSTAR flight vehicles is for accurate flight data ranging from air data measurements to inertial and control system parameters. To meet this goal, the AirSTAR vehicles are outfitted with precision air data probes, shown in figure 1, that measure total pressure, static pressure and wind incidence angles. Therefore, this instrumentation necessitates accurate calibrations, including expected corrections for static port position, and total pressure losses. The pitot-static system uses calibrated transducers for measurements of differential and static pressures. Due to the nature of the flight dynamics and controls research on the AirSTAR vehicles, instrumentation (including pitot-static measurements) are time sampled at rates up to $200 \mathrm{hz}$ and are available for near real-time or post-flight analysis. 


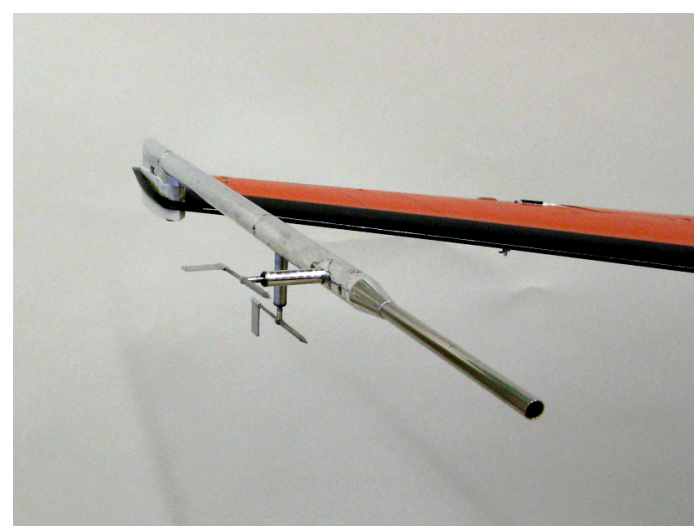

Figure 1. Photo of Air Data Probe.

The AirSTAR concept of operations involves vehicle control using radio frequency (RF) systems with direct line-of-sight piloting for safety purposes. Because of the within-visual-range (WVR) requirement, the flight test airspace is circular in shape with approximately one-half mile radius that limits the time for steady straight and level flight. These limitations precluded the use of conventional calibration methods, such as tower fly-by or pacer aircraft, and they were a primary motivation for a pitot-static calibration method that did not require multi-leg ground tracks and that minimized the need for sustained steady trim conditions.

The primary research objectives were as follows;

- Develop a method to rapidly estimate dynamic pressure sensing errors using GPS-derived ground speed data

- Integrate the method as a risk reduction and system monitoring tool in AirSTAR flight operations

- Address applications to emerging health monitoring technologies for transport airplanes

This paper presents the calibration results from two aircraft, the "S-2" single engine aircraft and the dynamically-scaled "T-2" twin engine aircraft which are shown in figure 2. Both aircraft utilized wing-tip mounted air data probes and the experiment was conducted at the NASA Wallops Flight Facility. The S-2 aircraft was flown to develop the initial calibration algorithms and the T-2 aircraft was used to demonstrate optimal calibration maneuvers and real-time calibration software.

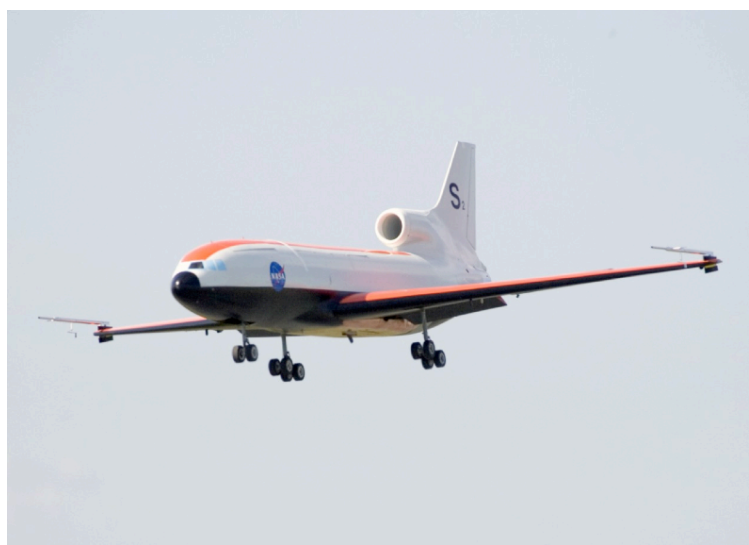

(a) Single Engine Airplane (S-2). 


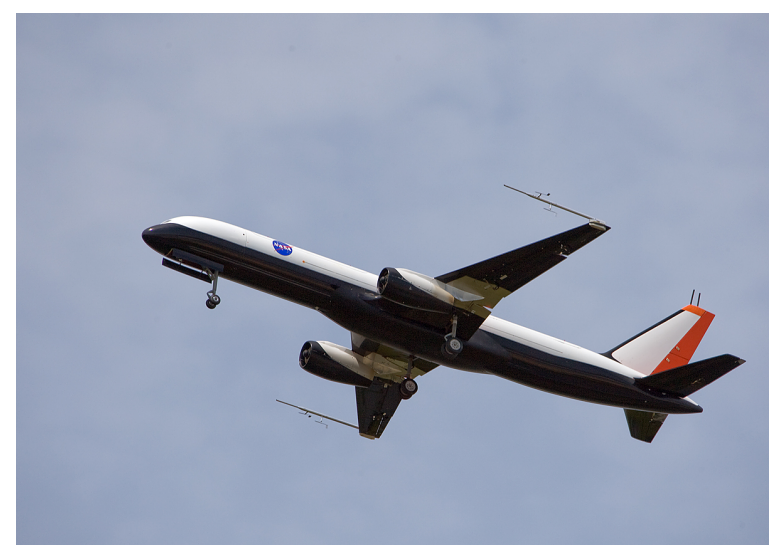

(b) Twin Engine Dynamically-Scaled Airplane (T-2).

Figure 2. Photos of Test Aircraft With Wingtip Air Data Probes Installed.

\section{Calibration Method}

Pressure-based airspeed and altitude systems are susceptible to errors in measurements of static and dynamic pressures. Typically static pressure errors are introduced by the disturbances in the flow field around an aircraft that necessitates careful positioning of static pressure ports to minimize this affect. Also, errors in dynamic pressure sensing from a pitot tube can be caused by excessive flow angularity or flow field interferences with the aircraft.

The approach to in-flight calibration methods generally involves comparison of onboard airspeed and altitude measurements with "truth data" such as ground referenced speed and altitude or measurements from a calibrated aircraft. A common practice for pitot-static system calibration is to assume all pressure errors are due to static pressure measurements that in turn are used to derive airspeed corrections. A typical format for airspeed correction data is shown in figure 3 for a light general aviation airplane.

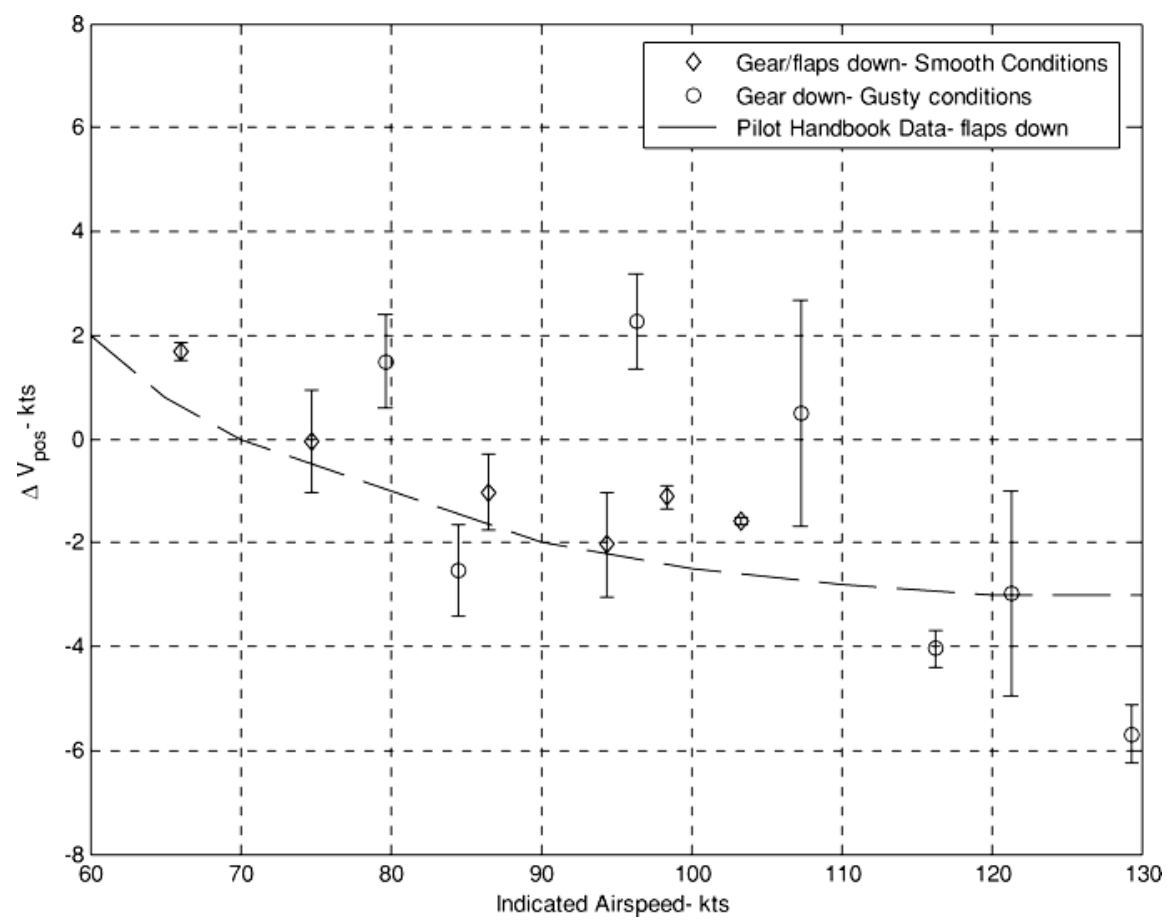

Figure 3. Example GPS-Based Airspeed Correction Measurements (reference 3). (Error Bars Indicate Least Squares RMS Error) 
Recent GPS based methods involve flying a defined flight track, such as a triangle or square, at constant airspeed and solving for the wind speed, wind direction and true airspeed (ref. 4-8). Calibrated dynamic pressure ( $\mathrm{q}_{\mathrm{c}}$ ) is then compared to the measured dynamic pressure $\left(\mathrm{q}_{\mathrm{ci}}\right)$ to compute the error in terms of static pressure and/or calibrated airspeed. Pressure errors are often presented in the form of normalized pressure error $\left(\Delta \mathrm{p} / \mathrm{q}_{\mathrm{c}}\right)$ versus measured dynamic pressure $\left(\mathrm{q}_{\mathrm{ci}}\right)$. This approach requires completion of multiple flight patterns for each airspeed and configuration that may require lengthy flight time and associated costs. In addition, it is assumed that the wind velocity and direction are constant throughout the maneuver.

Rather than focus on measurements and calibration at multiple fixed airspeeds, the approach used for this research was to identify an optimal model of pressure error, as a function of dynamic pressure throughout the speed range tested. The proposed method involves a continuous flight pattern within the range boundaries, over a range of airspeed, and high rate pressure measurements are acquired and recorded continuously for each flight pattern. For this experiment, the test vehicles were outfitted with previously described wingtip probes that were plumbed to onboard pressure transducers to acquire static and dynamic pressure measurements. A sample rate of $50 \mathrm{hz}$ was chosen for this experiment however data rate requirements may warrant further investigation. An illustration of the data acquisition system is shown in figure 4.

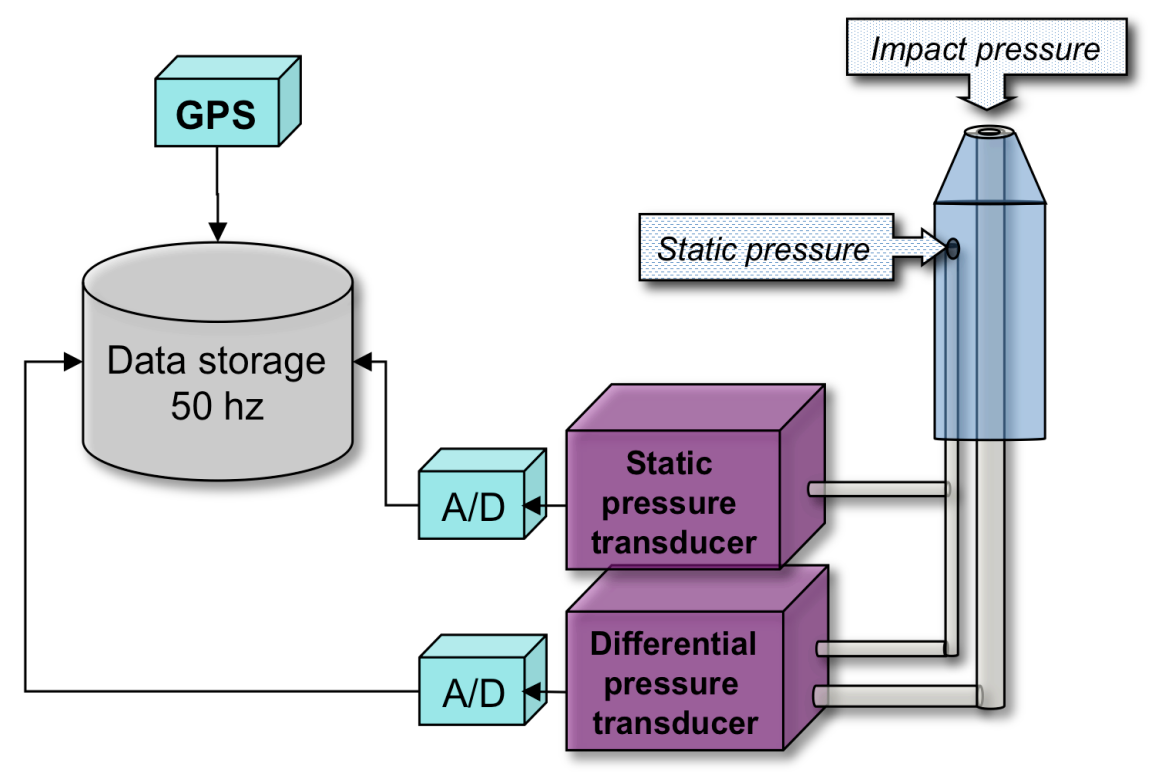

Figure 4. Illustration of AirSTAR Pitot-Static Data Acquisition System.

System identification methods, using output-error optimization, were used to generate the continuous pressure error function over the range of airspeed tested. The optimization algorithm used for this research was based on the System IDentification Programs for AirCraft (SIDPAC) toolbox for Matlab®. The output error routine (OE) was used as the primary tool for identification for model parameters and the routine is described in reference 9.

The equations for model identification were as follows;

$$
\begin{aligned}
& \text { (1) } \Delta \mathrm{p}=\mathrm{q}_{\mathrm{c}}-\mathrm{q}_{\mathrm{ci}} \\
& \text { (2) } \mathrm{q}_{\mathrm{c}}=1 / 2 \rho \mathrm{V}_{\mathrm{t}}{ }^{2} \\
& \text { (3) } \mathrm{V}_{\mathrm{t}}=\left(\mathrm{V}_{\mathrm{tn}}{ }^{2}+\mathrm{V}_{\mathrm{te}}{ }^{2}\right)^{1 / 2}
\end{aligned}
$$

where; 
(3a) $\quad \mathrm{V}_{\mathrm{tn}}=\mathrm{V}_{\mathrm{gn}}+\mathrm{V}_{\mathrm{w}} * \cos \Psi_{\mathrm{w}}$

and,

(3b) $\quad \mathrm{V}_{\mathrm{te}}=\mathrm{V}_{\mathrm{ge}}+\mathrm{V}_{\mathrm{w}} * \sin \Psi_{\mathrm{w}}$

The pressure error model can be of various forms as illustrated in figure 5. For the purposes of this research, the following function (inverse+) was used because it was deemed to be the most representative of typical static pressure errors on airplanes;

(4) $\quad \Delta \mathrm{p} / \mathrm{q}_{\mathrm{c}}=\mathrm{k}_{1}+\mathrm{k}_{2} / \mathrm{q}_{\mathrm{ci}}$

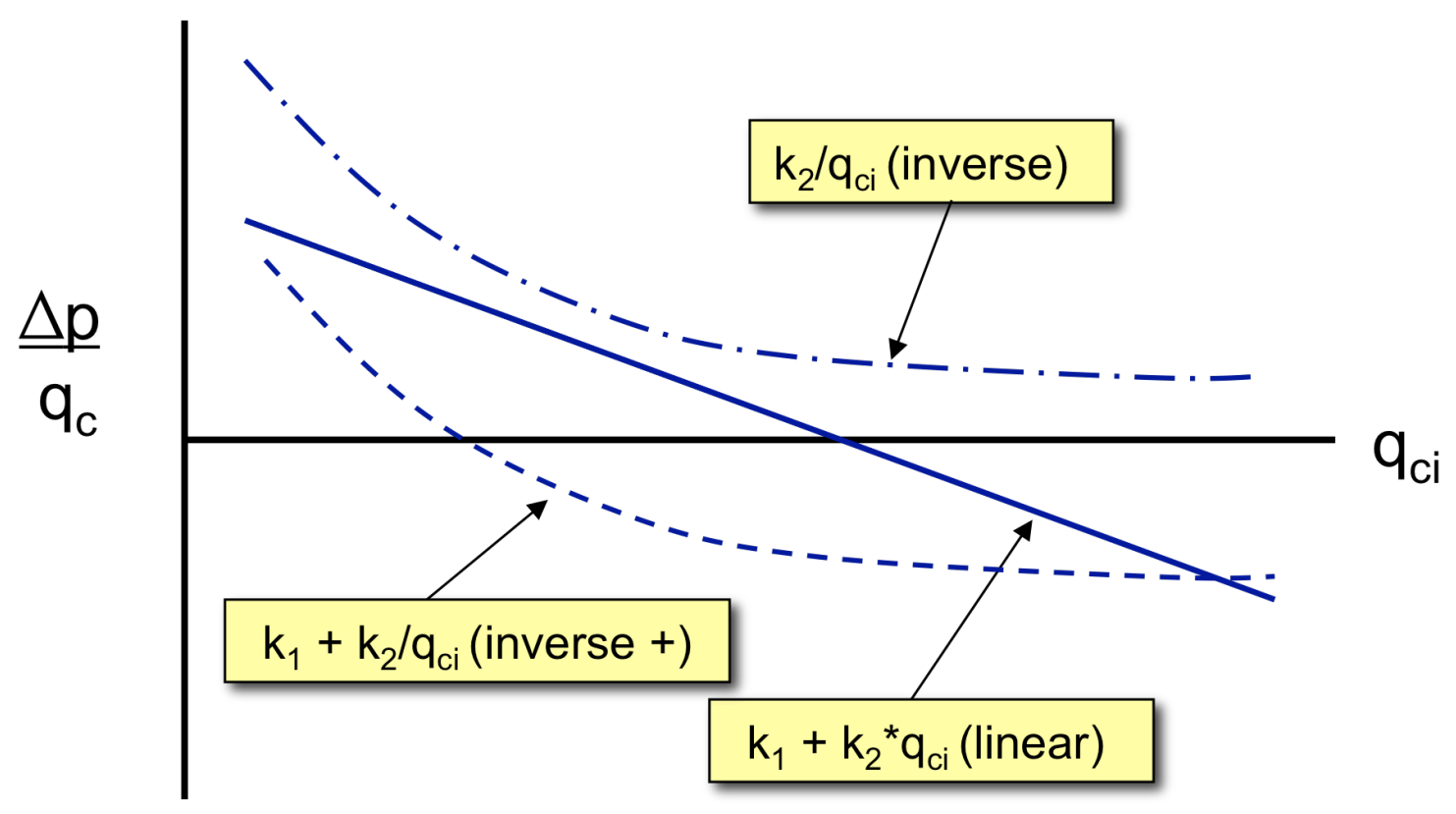

Figure 5. Illustration of Pressure Error Model Structures.

\section{Maneuver Criteria}

Maneuver criteria for conventional in-flight calibration methods usually include requirements for steady test conditions to minimize effects such as pressure lags or flow unsteadiness. Due to the limitations for maintaining steady test conditions, the following maneuver criteria were proposed;

- $\quad$ Airspeed should be quasi-steady to minimize pressure sensing lag effects

- Angle of attack effects should be considered; however, these are minimal for typical cruise speeds. The minimum airspeed should be chosen to minimize angle of attack effects. 
- Test conditions should be at nearly constant altitude and over a small geographic area to minimize variations in wind speed and wind direction.

- Vehicle maneuvering should be limited to mild turns to minimize angular rate effects on local airflow

\section{Flight Test Results}

A common first step in model identification experiments is to define accuracy requirements. One flight maneuver was examined using the S-2 aircraft that comprised approximately 16000 data points over 320 seconds (@ $50 \mathrm{hz}$ ) predominantly at two airspeeds, 70 and 90 KCAS. The algorithm was run with varying amounts of data ranging from to 750 to 16000 points to assess the effect on model parameters and confidence intervals. Figure 6 shows the variation of model parameters $\mathrm{p} 1, \mathrm{p} 2$ (corresponding to pressure error model parameters, $\mathrm{k}_{1}$ and $\mathrm{k}_{2}$ respectively), p3 (wind direction, $\Psi_{\mathrm{w}}$ ), $\mathrm{p} 4$ (wind velocity, $\mathrm{V}_{\mathrm{w}}$ ) and the confidence intervals for $\mathrm{p} 3$ (crb3) and $\mathrm{p} 4$ (crb4). The wind velocity and direction were nearly constant with a small sample size. The variation of parameters p3 and p4, as well as the confidence intervals indicated that at least 10000 samples were needed to converge to a stable solution. For two speed conditions, this required a dwell time of approximately one to two minutes at each airspeed. It is important to recognize that this variation of parameters with sample size is due to system characteristics such as noise, turbulence, and transducer sensitivity that could change for different aircraft or atmospheric conditions. Also, depending on the overall accuracy requirements, the dwell time may be reduced. Important influences on overall accuracy are:

- GPS groundspeed accuracy

- Pressure transducer sensitivity

- Pressure transducer calibration

- Turbulence levels
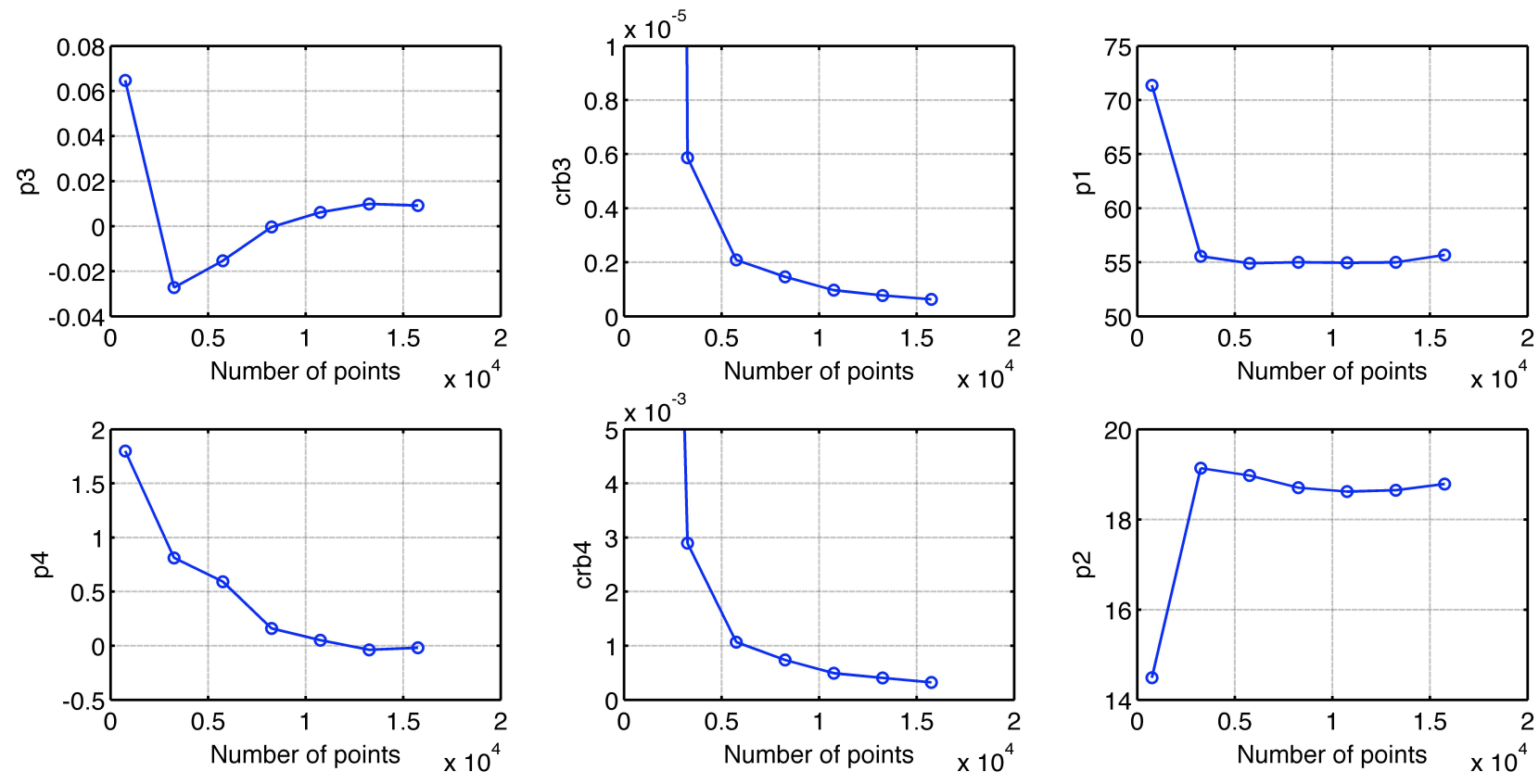

Figure 6. Effect of Sample Size On Identified Calibration Parameters, S-2 Aircraft. 
Based on the results in figure 6, the calibration for 10751 points was derived and is shown in figure 7 . The data distribution shows most of the points are near the minimum or maximum airspeeds. The overall airspeed error is nearly constant for all speeds at approximately $0.5 \mathrm{kts}$ and the $2-\sigma$ confidence interval is less that $0.2 \mathrm{kts}$. To illustrate the influence of sample size on the results, the calibration using 5751 points is shown in figure 8 . For this result, the pressure and airspeed error shows some variation with airspeed, however the 2- $\sigma$ confidence interval is nearly the same. In both cases it may be concluded that the overall system error ranges from approximately 0.5 to $1.0 \mathrm{kts}$ with small confidence boundaries. Small differences in the predicted wind speed and direction are indicated as well.

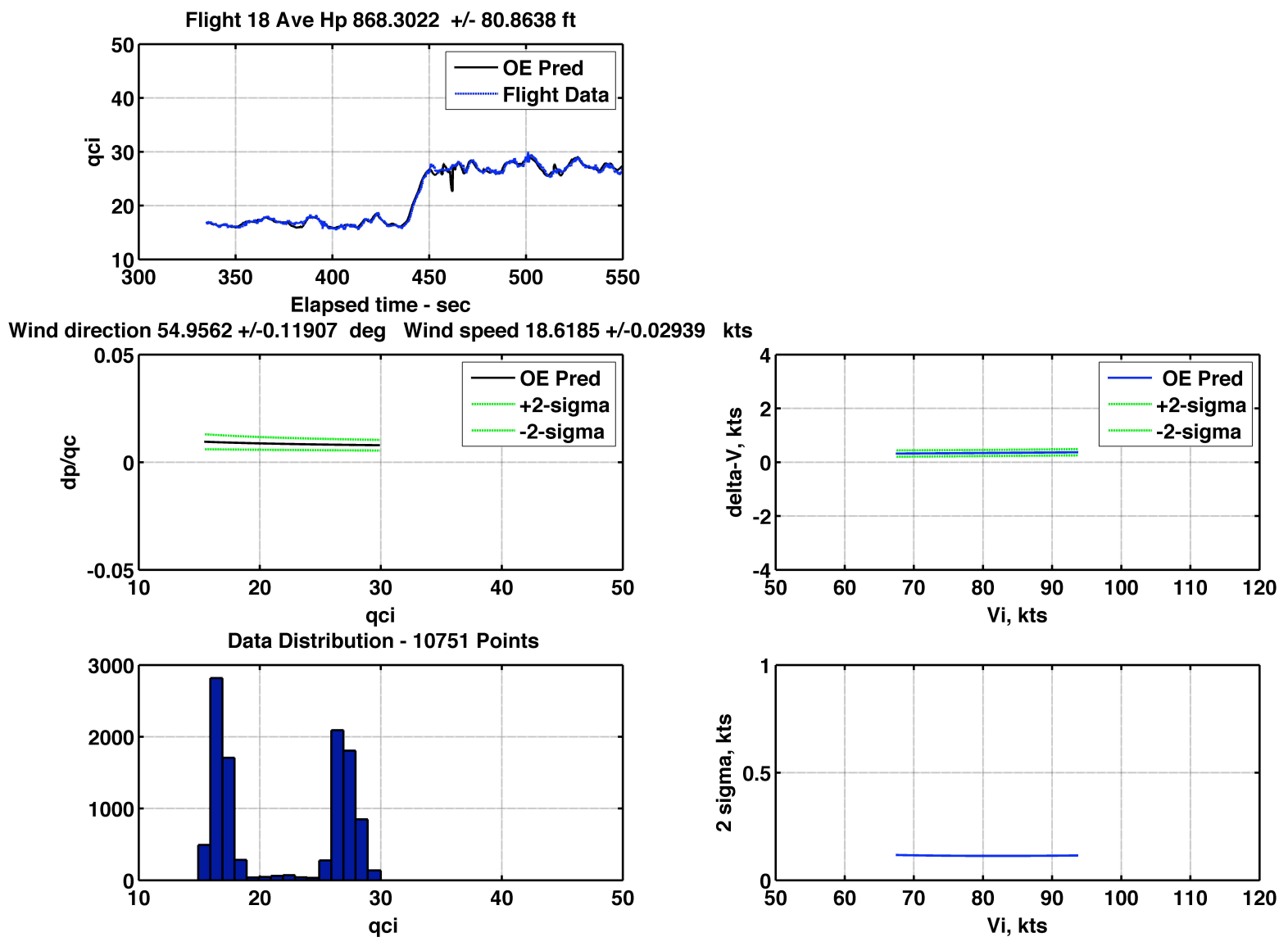

Figure 7. Calibration Results, 10751 Data Points, S-2 Aircraft. 

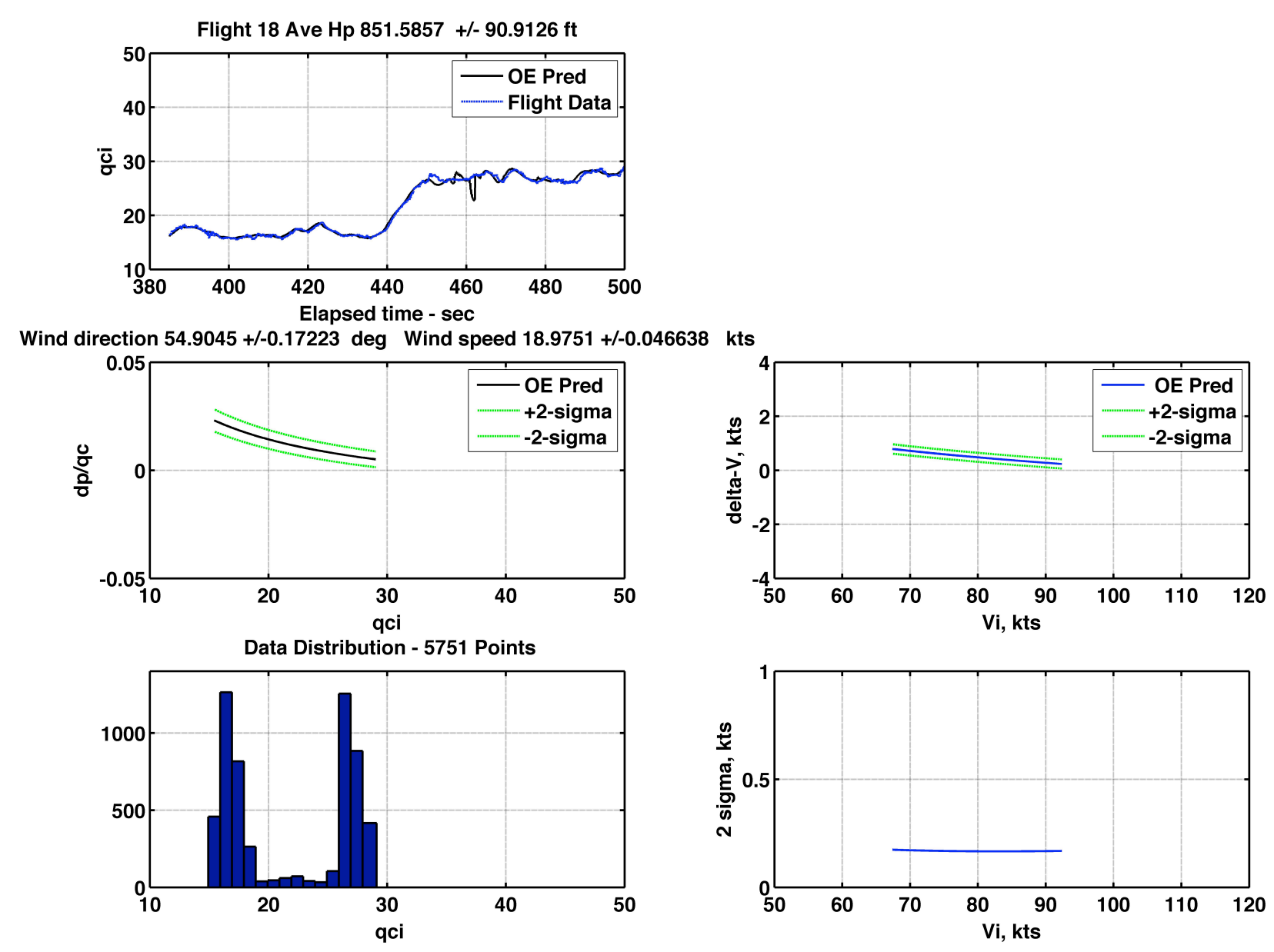

Figure 8. Calibration Results for 5751 Data Points, S-2 Aircraft.

Based on the S-2 flight test results shown in figures 6-8, optimized maneuvers were designed and tested using the T-2 aircraft. Because output error methods can be affected by data distribution, an important consideration in designing calibration maneuvers was the distribution of dynamic pressure measurements over the range of dynamic pressures tested. Therefore, two airspeed maneuver profiles were designed to minimize non-uniform data effects; 1 ) step and pause and 2) continuous acceleration; at airspeeds from 70 to 100 KCAS. Figure 9 shows airspeed versus time for each profile. For the step and pause maneuver, the target airspeed is maintained for approximately 60 seconds followed by a rapid acceleration to the next airspeed. For the continuous acceleration maneuver, airspeed is slowly increased over a time period of 240 seconds. Note that the variation of airspeed with time is non-linear in order to maintain a uniform distribution of pressure measurements. 


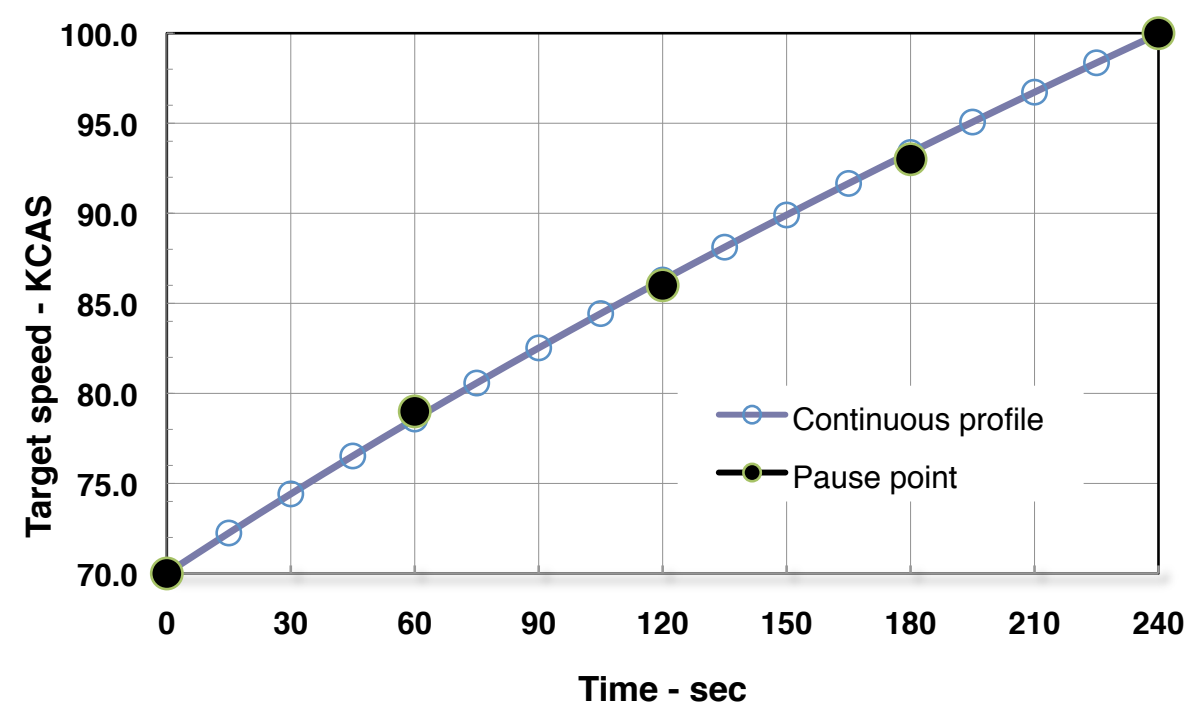

Figure 9. Airspeed Profiles for T-2 Calibration Maneuvers. Continuous Acceleration, Step and Pause Maneuvers.

Calibration results for the step and pause maneuver and the continuous acceleration maneuver are shown in figures 10 and 11 respectively. Both maneuvers were flown sequentially on one flight to allow a comparison between the two methods with similar wind conditions. The desired maneuver criteria were to maintain altitude $+/-$ $50 \mathrm{ft}$ from the target altitude $(800 \mathrm{ft})$ and airspeed +/- 5 KCAS from the target value. Desired performance was achieved for both maneuvers with satisfactory pilot workload. Both maneuvers yielded similar calibration results with absolute airspeed errors less than 0.5 KCAS and 2- $\sigma$ confidence intervals less than $0.2 \mathrm{KCAS}$. Also, the predicted wind speed and direction were very similar for both methods. The step and pause maneuver required more time to complete due to the time required to change airspeeds however further study is required to optimize sample size and data distribution for this maneuver. 

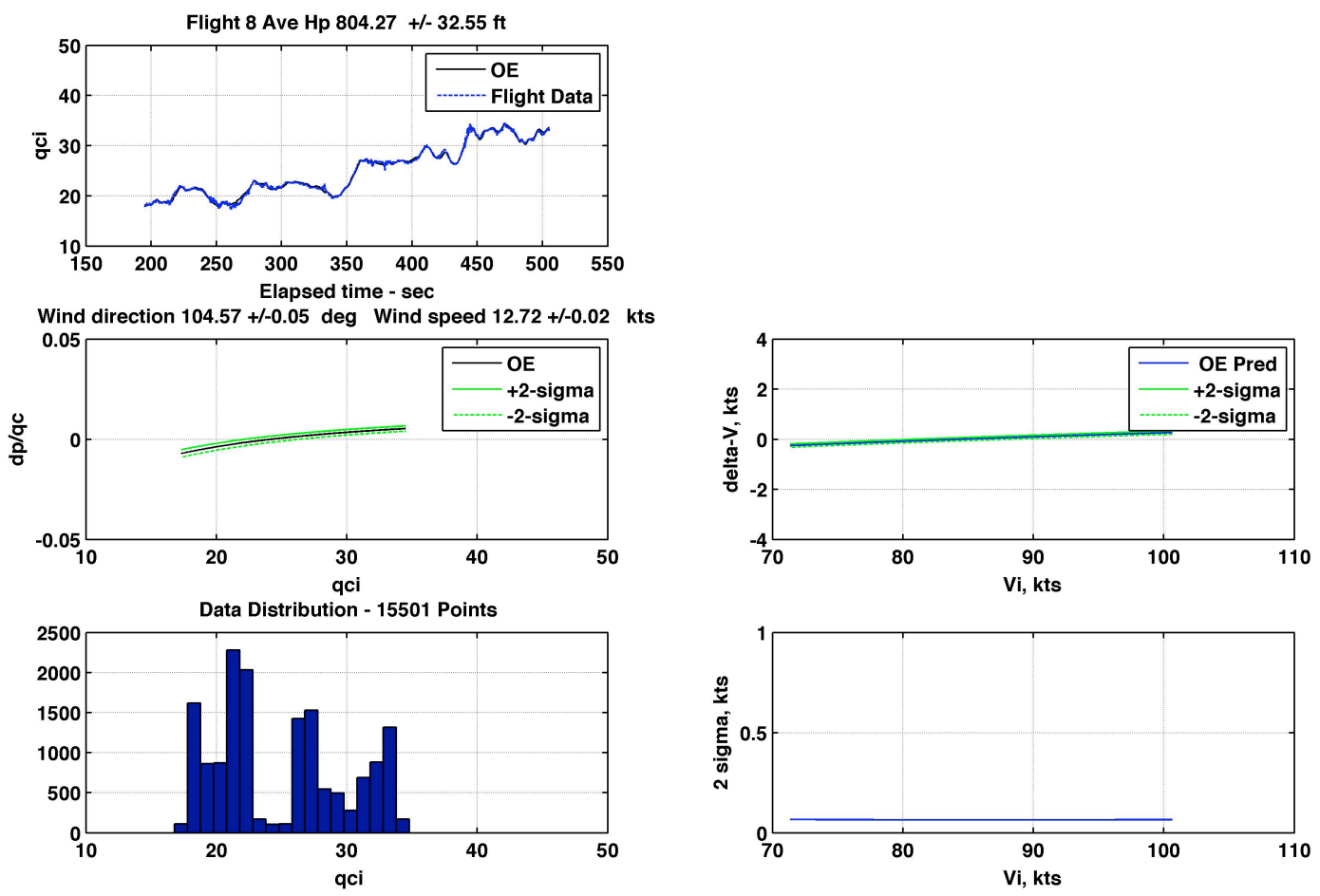

Figure 10. Calibration Results For Step and Pause Maneuver, T-2 Aircraft. 

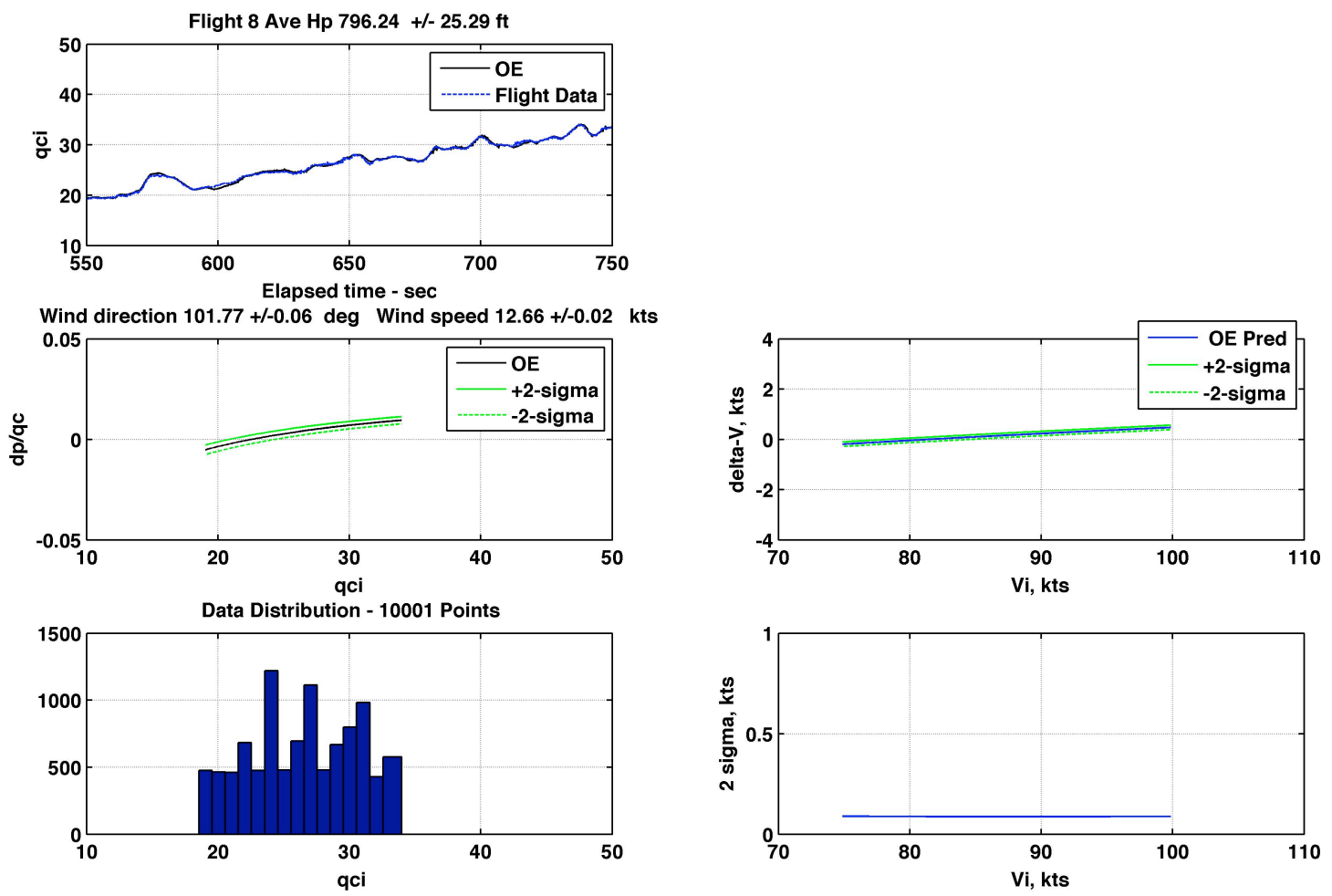

Figure 11. Calibration Results For Continuous Acceleration Maneuver, T-2 Aircraft.

\section{Validation Approach}

Although the output from the optimization routine includes confidence intervals for the identified pressure error model, the desire remains to provide validation of the overall approach. Because the algorithm computes predicted wind direction and velocity, wind measurements were acquired as part of the flight experiment for the purpose of comparison to the predicted values. For these tests conducted at the NASA Wallops flight facility, a tethered balloon (Aerostat) carrying wind measurement instrumentation was used to acquire wind direction and velocity simultaneously with the flight experiment. The tethered balloon was located approximately $1 \mathrm{~nm}$ from the center of the flight test operations are. The Aerostat facility is illustrated in figure 12. 


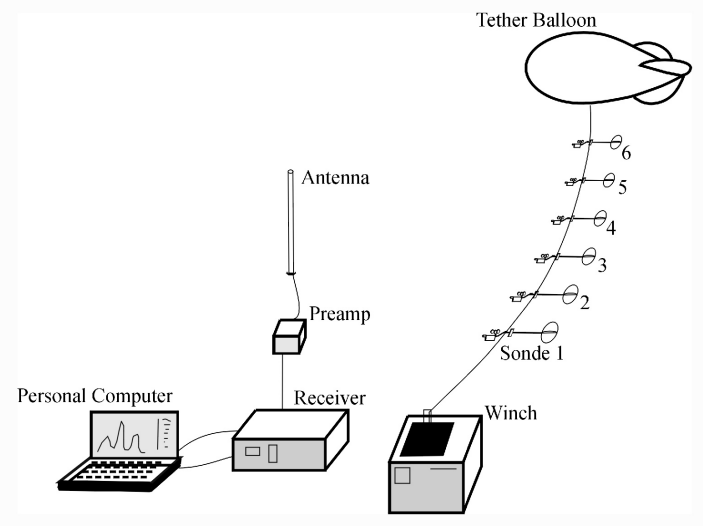

Figure 12. Illustration of Aerostat Wind Measurement System.

A comparison of wind speed and direction from the output error algorithm and the Aerostat wind measurements is shown in figures 13 and 14 for the step and pause and continuous acceleration methods respectively. Note that the flight calibration profiles were flown at approximately $800 \mathrm{ft}$ altitude. Both methods show agreement within approximately $0.5 \mathrm{KCAS}$ wind speed and approximately 4 degrees wind direction.
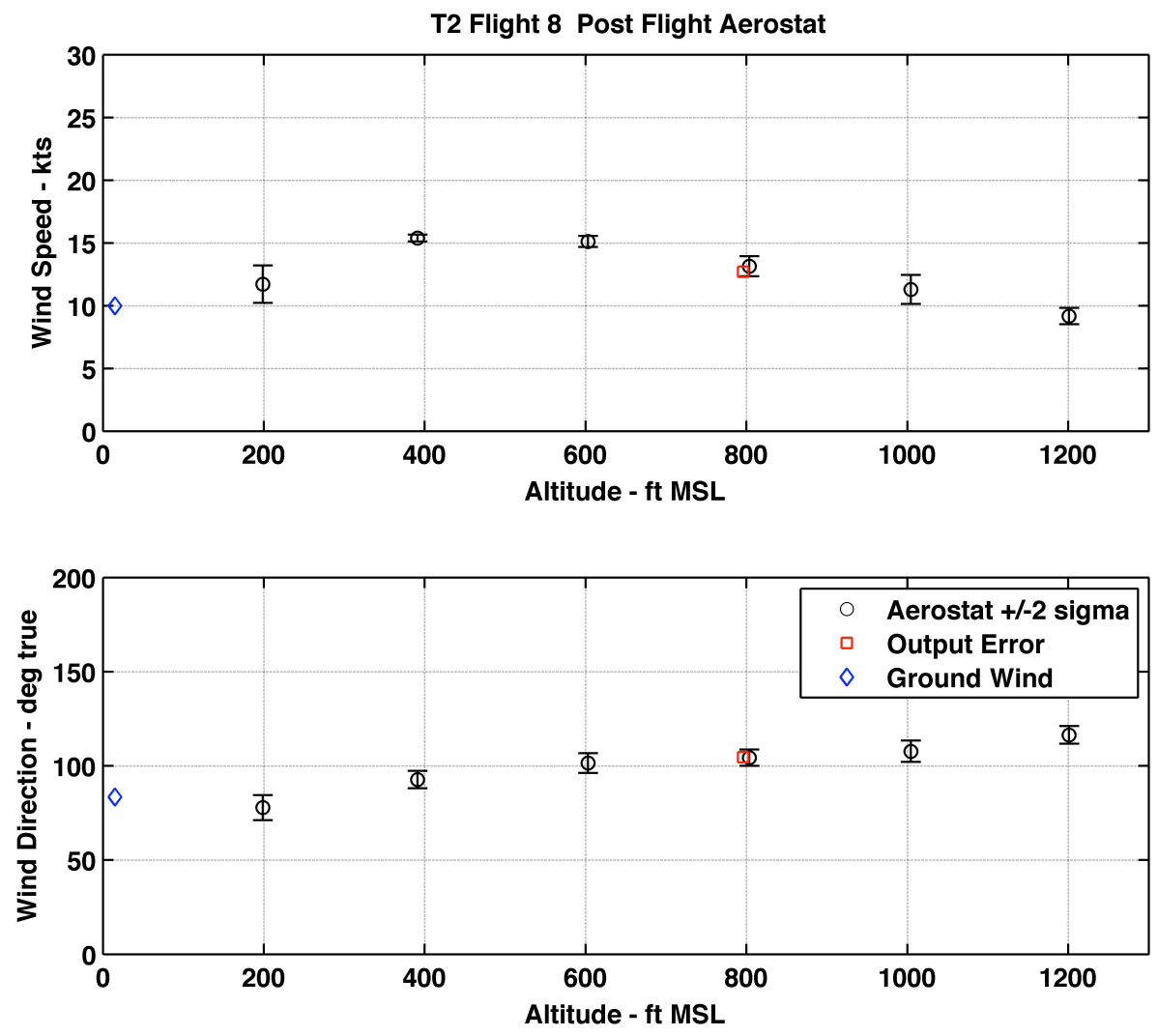

Figure 13. Comparison of Aerostat Wind Speed Measurement to Output Error Prediction, Step and Pause Maneuver at $800 \mathrm{ft}$ Altitude, T-2 Aircraft. 

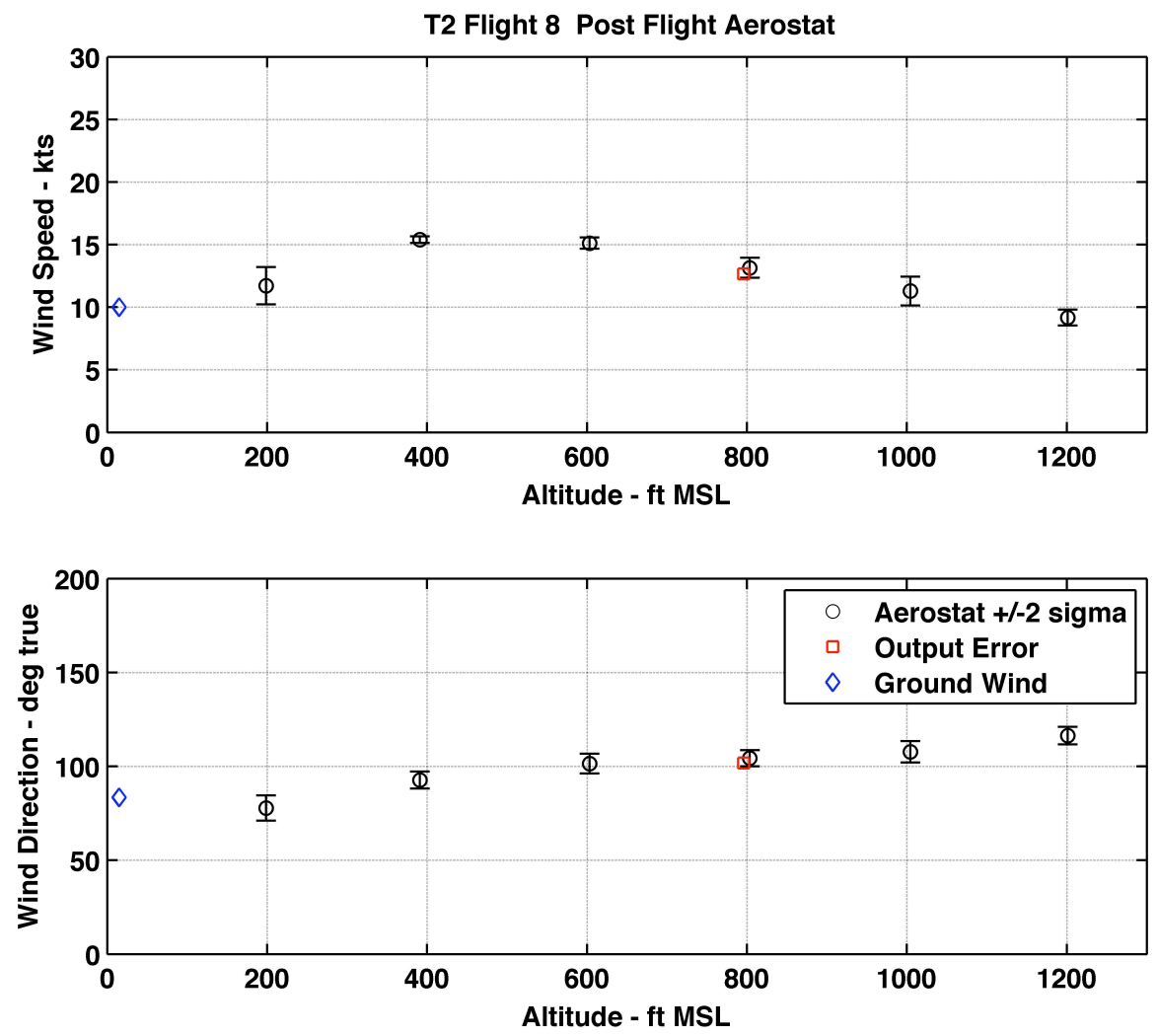

\section{Figure 14. Comparison of Aerostat Wind Speed Measurement to Output Error Prediction, Continuous Acceleration Maneuver at $800 \mathrm{ft}$ Altitude, T-2 Aircraft.}

\section{Potential Applications}

\section{A. Research Flight Operations}

The application of rapid onboard calibration was found to be useful for AirSTAR flight operations. Only one sortie lasting approximately 10 minutes was required to complete the calibration maneuvers. In addition, the calibration constants were computed in near real-time without the need for lengthy data analysis between flights. For the T-2 flight test, the calibration estimates were computed within $16 \mathrm{sec}$ after completion of the maneuver using a laptop computer. This capability allowed a rapid assessment of the airspeed sensing system early in the flight test program prior to conducting high-risk maneuvers that rely on accurate airspeed information.

\section{B. System Monitoring and Fault Detection}

An emerging technology known as "health monitoring" is becoming recognized as a potential mitigation for aircraft accidents due to loss of control. This technology relies on the ability to monitor critical flight parameters to detect potential failures in sensors, actuators or other onboard systems. For example, faulty airspeed measurements have been identified as a causal factor in accidents that lead to stall and departure from controlled flight. A near real-time method that can detect errors in air data measurements could provide identification of degrading systems allowing action to be to prevent an accident.

Figure 15 shows an example of a prototype airspeed monitoring system that was run real-time during T-2 test flights involving various maneuvers. The upper left hand display shows a continuous comparison of real-time 
dynamic pressure measurements compared to the calibration from the optimal output-error method. The remaining three displays show parameters for the purpose of monitoring flight condition. For this example, the red symbols denote where the real-time pressure measurement failed stringent error detection criteria. Further research is planned to develop error detection criteria addressing maneuver requirements, false alarms, and display concepts.
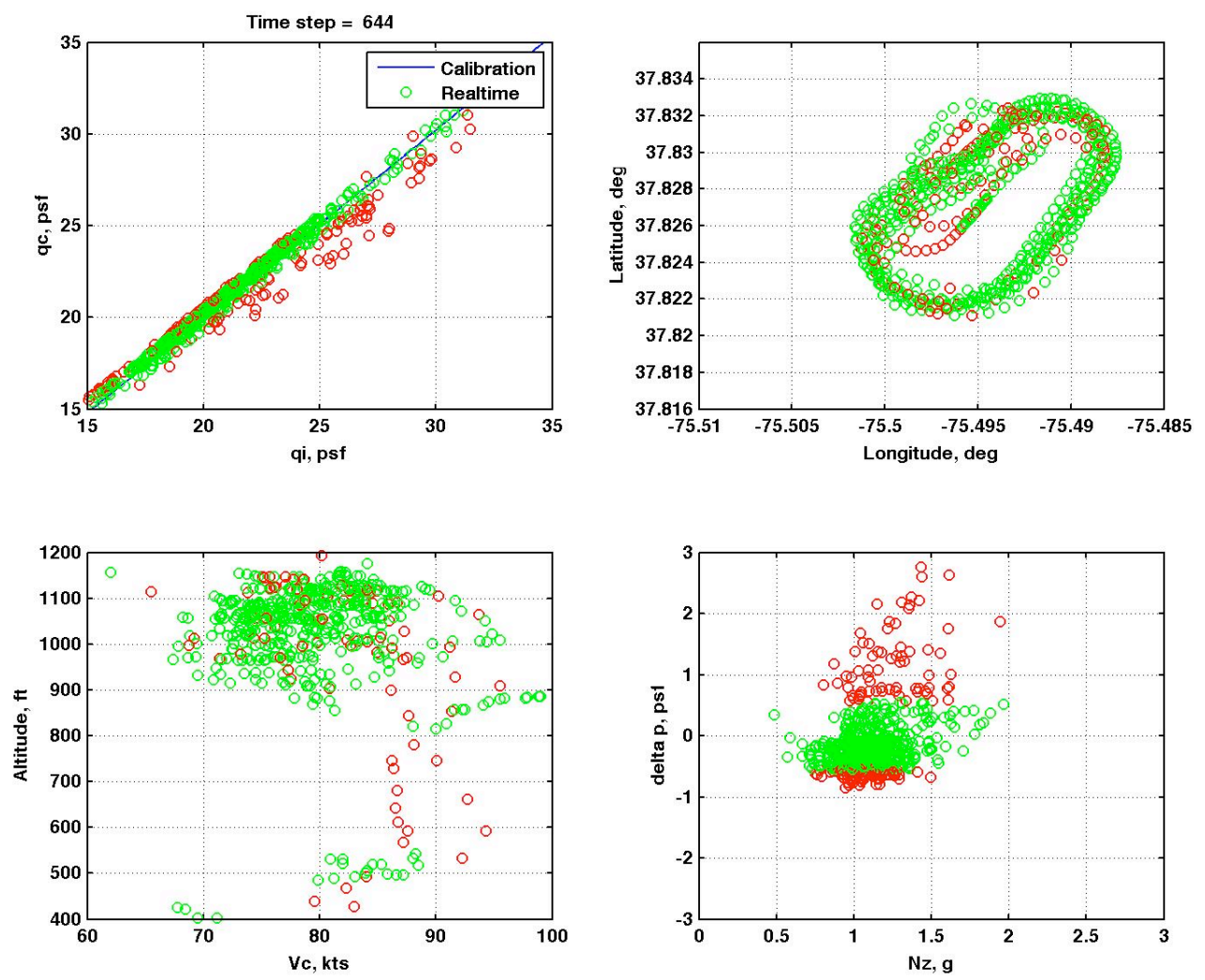

Figure 15. Example Airspeed Health Monitoring Display.

\section{Summary}

A GPS-based inflight pitot-static calibration method has been developed for the NASA AirSTAR flight program. The method uses a global output error method to identify an optimal model of the pressure error as a function of dynamic pressure. Advantages of this method include short test time requirements, statistical control over calibration accuracy, and potential for near real-time applications. Flight test data from wing-tip mounted probes on a turbine-powered subscale aircraft identified system errors of approximately 0.5 KCAS with corresponding 2- $\sigma$ confidence boundaries of 0.2 KCAS. Estimated wind speeds from the calibration algorithm were within 1 knot of measurements from a tethered balloon taken concurrently with the flight experiment which served as a validation of the output error approach.

The output error calibration method was demonstrated within a confined flight test area that would not be large enough for conventional calibration methods. However, an advantage of the small test area was that the wind speed and direction may not have varied as much as that using a larger test area, potentially improving accuracy of the calibration results. Based on the data rate used for this experiment, the continuous acceleration maneuver was 
identified as a suitable approach to achieve desired calibration accuracy and ease of flying the test maneuver. A dwell time of approximately one minute for a $10 \mathrm{kt}$ airspeed interval was found to provide desired accuracy. An auto-throttle control system should be considered as a method to improve airspeed control and reduce pilot workload.

A concern regarding this test method was the requirement for steady flight conditions (precise airspeed control) typically used for conventional airspeed calibration methods. For the purposes of this experiment, dynamic pressure measurements were recorded throughout the calibration maneuver, including varying airspeed and turns, to illustrate the potential inaccuracies introduced by the non-steady conditions. Based on the results to date, the effect of angular rate, slowly varying airspeed or other non-steady conditions did not appear to have a significant effect on the results. Further analysis is recommended to determine the limitations of maneuver quality on calibration accuracy. Also, further investigation of data rate requirements is warranted.

While this experiment was focused on installed pitot-static system calibration, the method described could have broader applications. As part of AirSTAR flight operations, this method can support system monitoring and risk mitigation, allowing rapid detection of airspeed system failure or anomalies. Further work is in progress to identify applications to onboard health monitoring technologies for large transport aircraft.

\section{References}

1. Jordan, Thomas L., Foster, John V., Bailey, Roger M., and Belcastro, Christine, M.; AirSTAR: A UAV Platform for Flight Dynamics and Control System Testing, AIAA-2006-3307.

2. Cunningham, Kevin, Foster, John V., Morelli, Eugene A., and Murch, Austin M.; Practical Application of a Subscale Transport Aircraft for Flight Research in Control Upset and Failure Conditions, AIAA-2008-6200, August, 2008.

3. Niehwoehner, Robert J., Refining Satellite Methods for Pitot-Static Calibration, Journal of Aircraft, Vol. 43, No. 3, MayJune 2006.

4. Kimberlin, Ralph and Sims, Joseph, Airspeed Calibration Using GPS, 6th AIAA Biennial Flight Test Conference, Hilton Head Island, SC, AIAA 92-4090, August 1992.

5. Knoedler, Andrew J., et al; Investigation of Global Positioning System Use for Air Data system Calibration, U.S. Air Force Test Pilot School, 1996.

6. Knoedler, Andrew J., et al; Investigation of Global Positioning AIAA-1996-3417-841, Atmospheric Flight Mechanics Conference, 1996.

7. Calibration of General Aviation Aircraft (HAVE PACER II), AFFTC-TR-95-76, Air Force Flight Test Center, Edwards AFB, CA, January 1996.

8. Lewis, Gregory; Using GPS to Determine Pitot-Static Errors, National Test Pilot School, 14 August 2003.

9. Klein, Vladislav and Morelli, Eugene A.; Aircraft System Identification, Theory and Practice, AIAA Education Series, 2006. 